\title{
Design and Fabrication of Biodegradable Antenna Using Jute Material for UWB Application
}

\author{
Kinol. A. Mary Joy $\mathbb{D}^{\mathrm{D}},{ }^{1}$ Marshiana Devaerakkam $\mathbb{D}^{\mathrm{D}},{ }^{2}$ D. Godwin Immanuel $\mathbb{D},{ }^{2}$ \\ Krishnamoorthy Narasu Raghavan $\mathbb{D D}^{2}$, Grace Kanmani Prince $\mathbb{D}^{2},{ }^{2}$ and Kassu negash $\mathbb{D}^{3}$ \\ ${ }^{1}$ Department of Electronics and Communication Engineering, Saveetha School of Engineering, Chennai, Tamil Nadu, India \\ ${ }^{2}$ School of Electronics, Sathyabama Institute of Science and Technology, Chennai, Tamil Nadu, India \\ ${ }^{3}$ Department of Mechanical Engineering, Faculty of Manufacturing, Institute of Technology, Hawassa University, \\ Hawaasa, Ethiopia
}

Correspondence should be addressed to Kassu negash; kassun@hu.edu.et

Received 3 December 2021; Revised 28 December 2021; Accepted 15 January 2022; Published 4 March 2022

Academic Editor: A. Parthiban

Copyright (c) 2022 Kinol. A. Mary Joy et al. This is an open access article distributed under the Creative Commons Attribution License, which permits unrestricted use, distribution, and reproduction in any medium, provided the original work is properly cited.

\begin{abstract}
Ultra-Large Band (UWB) is a radio technology used for the transmission and distribution of radio energy over a wide frequency band with low power spectral density. A newer UWB Microstrip patch antenna is designed using a jute material as a substrate because of its durability and $\mathrm{CO}_{2}$ and water footprint. The ecological impact is relatively small with Cradle to Cradle, biodegradable with $100 \%$ compostable, and extremely strong. The jute substrate is reinforced to make it nonflexible and hydrophobic for further better electrical and mechanical properties, and it is treated with the conductive polymer sodium alginate; the results were compared with the raw hydrophilic jute substrate. The proposed antenna design and results were compared with the similar antenna using the FR4 substrate of a dielectric constant of 4.4 and a thickness of 1.6, and the ultra-wideband spectrum range from 3.1 to $10.6 \mathrm{GHz}$. It is used for both uplink and downlink transmission of local area network (LAN), wide area network (WAN), and satellite communications spectrum (SCP). The performance of this network provides a wider bandwidth transmission for the range of 1 to $14 \mathrm{GHz}$ applications.
\end{abstract}

\section{Introduction}

Several types of antennas with different substrates and with different shapes were available on market. Implementing some novelty work by using a new material as a substrate and also using a new shape has to be developed. The new material considered for this technique is jute which is the first one to implement as a substrate. Jute is selected, because it is very cheap, reliable, and commercial compared to other materials such as silicon, FR4, Tachonic, RT Duroid, and Rogers. Since some materials other than jute are nonbiodegradable, the disposal of such materials will harmfully affect our environment and also lead to some human health issues. So jute is used as a substrate for the antenna to overcome these issues since it is biodegradable and ecofriendly to the environment. Compared to other materials, jute is flexible and wearable. Jute is said to be a biodegradable material that can be easily decomposed after its usage. The novel approach to this technique is due to the material used for the transmission purpose. Nowadays, nonbiodegradable materials are being used which are difficult for disposal when not in use. To avoid this, newer decomposable jute material was developed for the uplink and downlink transmission.

Compact antennas are always a difficult task in the antenna domain. We need to achieve a compact antenna design, but because of its smaller size it cannot be easily defined as an antenna by others. So it can be used in tracking and detective applications. The antenna size reduction process is always a challenging one. It is restricted by some fundamental physical limits. The frequency range gets increased with decreases in the size of the antenna, respectively. To obtain a wider frequency range, we are designing a 
compact size antenna. Since it is small in size, it is easy to carry and also useful for wearable applications. Larger size antennas are limited with respect to their frequency in the $\mathrm{MHz}$ range and they are also very difficult to maintain and handle compared to compact antennas.

The compact, high bandwidth ground plane is made of FR4 dielectric material with a height of $1.6 \mathrm{~mm}$ and an $r$ of 4.4 for wireless applications. A bandwidth between $2.33 \mathrm{GHz}$ and $12.4 \mathrm{GHz}$ was achieved and broadly covers the ultrabroadband range from $3.1 \mathrm{GHz}$ to $10.6 \mathrm{GHz}$. Area network, satellite communications, and local area network (for both uplink and downlink) [1] antenna for ultra-wideband applications with SRR using CPW power was developed with Taconic dielectric material with a dielectric constant of 2.33 . The results show that this antenna reaches the bandwidth ranges of $2.37 \mathrm{GHz}$ to $10.93 \mathrm{GHz}$ and the subbandwidth of $128.7 \%$. It shows that the cheaper FR4 substrate, compared to Taconic, is used and also offers a better improvement in profit [2].

The planar antenna for ultra-broadband applications was developed using the dielectric material RT Duroid Rogers RO3003h with a dielectric constant of 3 . Results obtained by this method achieve a bandwidth antenna range of $2.5 \mathrm{GHz}$ to $12 \mathrm{GHz}$ with a bandwidth share of $131.1 \%$. It is better than the flat UWB antenna in [3]. The author suggested that that textile antenna having a dual-band for implementation in WLAN techniques is configured using a coplanar waveguide (CPW) configuration. The transmission is based on the jute material antenna, which has a dielectric constant of 1.31 and works in the 2 to $2.57 \mathrm{GHz}$ band and the $4.26 \mathrm{GHz}$ to $6 \mathrm{GHz}$ band and the WLAN operating bands of 2.4/5.2/Covers $5.8 \mathrm{GHz}$. The antenna, designed with the jute substrate, covers the ultra-broadband range from $3.1 \mathrm{GHz}$ to $10.6 \mathrm{GHz}$, the LAN, the WAN, and also the field of satellite communication [4].

Using the dielectric material RT Duroid Rogers R4003B with a dielectric constant of 3.4 , a compact square micro band slot antenna was analyzed and developed for ultrawideband applications. The transmission is achieved by the bandwidth of $3 \mathrm{GHz}$ to $11 \mathrm{GHz}$ with a broad break band of $114.2 \%$. The antenna area is $12000 \mathrm{~m}^{2}$. The designed antenna is compact with an area of $1720 \mathrm{~m}^{2}$ and also shows better results [5]. A relatively newer concept in several studies is the consideration of natural fibres as reinforcement material. Nonbiodegradable polymers are made from petroleum and fibres such as phenol, polyester, and PP. Polymer matrices are becoming expensive due to volatile petrochemical prices. These resins could be made affordable by switching to cheaper bioresources. These fibres are renewable, nonabrasive for process equipment, and also very safe to handle, process, and use. Natural fibre "jute" is a relatively newer concept as a substrate [6].

Dynamic parameters of the jute fibre are such as storage modulus $\left(\mathrm{E}^{\prime}\right)$, loss modulus $\left(\mathrm{E}^{\prime \prime}\right)$, and damping factor (Tan $\delta)$, which are temperature-dependent and there is information about the interfacial bond between the reinforced fibre and the polymer matrix of the composite material. This review article is designed as a widespread of published articles on dynamic mechanical properties of natural fibre with reinforced polymer composites, hybrid, nanocomposites, and their uses. In the proposed antenna project [7], the dynamic parameters of the substrates were changed. About the application of the hydrophilic jute fibre along with hydrophobic resin by making the hydrophobic fibre, the feasibility of the lactase-mediated dodecyl gallate (DG) graft can be invested for a minimum of 30 minutes on the jute fibre. It was analyzed that the surface hydrophobicity of the jute fabric was increased. The flouting force of the modified jute/PP composite material was also improved and the breaking segment became clean and normal due to the DG laccase-assisted grafting. Inherently hydrophilic jute material is hydrophobically modified for use as an antenna [8]. Lignocellulose fibres show excellent potential in the paper industry and various applications. Alternatively, lignocellulose fibres are best suited candidates for high-tech applications in the area of environmentally friendly flexibility, fullness, and lightness. The paper rolls were made with lignocellulose fibres from a self-cultivated plant [9].

The adjustable paper rolls had a tensile strength of 9.1 MPA and were also used as a substrate in a patch antenna to perceive dielectric properties. The antennas were designed with a dielectric constant and resonance frequency of 3.71 and $5.1 \mathrm{GHz}$, which generates a revisit loss of $10 \mathrm{~dB}$ and offers the possibility of miniaturizing size and weight compared to an antenna based on Jean-Substrate. This article will help you to find and understand the various parameters of the natural fibre jute [10]. In this article, they proposed a CPW Fed patch antenna with a frequency band of $\mathrm{L} 1(1.67 \mathrm{GHz}$ to $1.90 \mathrm{GHz})$ and $\mathrm{L} 2(2.65 \mathrm{GHz}$ to $3.05 \mathrm{GHz})$. In the analysis with the moment method, the bandwidth of the proposed antenna reaches around $230 \mathrm{MHz}$ and $400 \mathrm{MHz}$ with a return loss of around $30 \mathrm{~dB}$ and $28 \mathrm{~dB}$ over the selected frequency spectrum $[11,12]$.

\section{Materials and Methods}

In this area, the discussion is about the substrate arrangement and strategies to plan the receiving wires and plan formulae and measurements of the proposed radio wires. Reenactment of the plan leads to the creation of the radio wire and testing the created receiving wire. Radio wires were planned by utilizing HFSS (tall recurrence structure test system).

2.1. Preparation of Jute Fibres to Jute Fabric. Jute has been used in India from prehistoric times. Jute was essential in the 19th and early 20th centuries. People were drawn to jute because of its low cost, strength, and adaptability. Jute fibre is 100 percent biodegradable and recyclable, making it a green choice. It grows in a short amount of time (4-6 months), making it useful for producing other food crops. It is called The Golden Fiber because it is a golden and silky natural sheen fibre. It is the simplest vegetable fibre obtained from the plants finest or skin. It is used in worldwide applications like production consumption and accessibility. It has high tensile strength and minimal extensibility and allows fabrics to breathe better. As an output, jute is ideal for bulk 
packaging of agricultural commodities. It aids in the production of high-quality industrialized yarn, cloth, web net, and bags. It is one of the mainly adaptable natural fibres, having been utilized as a raw material in the wrapping, agricultural, textile, and other construction industries. The uses of jute encompass properly insulating and antistatic residences, in addition to having lower thermal conductivity and slight moisture regain. Other benefits of jute encompass acoustic insulating residences and manufacture without pores and skin irritations. Jute's capacity is that it can be combined through different fibres, both artificial and also natural accepting cellulosic dye lessons which include natural, basic, vat, sulfur, reactive, and pigment dyes. The ensuing jute/cotton yarns will make fabric through a discounted fee of moist dispensation treatments. Figure 1 represents the process of preparing jute fabric from the jute fibres.

2.2. Substrate Preparation. The antenna for the proposed mission, now no longer the handiest, makes use of the commercial FR4 epoxy substrate; it additionally incorporates jute as an antenna substrate. The jute substrate used right here differs in structural, physical, mechanical, and electric belongings wherein every cloth had been synthesized in a special percentage of chemicals.

\subsubsection{Step-by-Step Procedure for Jute Composite Fabrication} Using Thermoset Resin. Figure 2 shows the subsequent steps to manufacture the jute composite using thermoset resin Impregnation and drying-jute substrate (nonwoven/woven fabric) is dipped in resin answer and squeezed to maintain the specified quantity of resin after being surpassed via dryer to lessen the moisture. The handled substrate is reduced to the required length. Compression moulding: books in the platen are hard-pressed to favour precise stress and heat for the predescribed duration to get the moulded product. The finishing touch of the compression cycle and its platens was cooled to the desired temperature and it is pressed and launched to get the merchandise. Postcuring compression: moulded merchandise was heated in an oven to get cured and unfastened from any condensate polymer. Cutting and sanding: the moulded product is trimmed and sanded.

2.2.2. Pretreatment of Jute Fabric. Commercially, $2 / 2$ twill material of 402 grams in step with rectangular meter (GSM) is used for this study. Jute materials become mild-scoured with $3 \%$ nonionic detergent (OWF) and 1\%TA (OWF) at $50^{\circ} \mathrm{C}$ for 60 mins with a 1:20 fabric to liquor ratio. After mild scouring, the samples were neutralized with an acetic acid solution, washed using bloodless liquid, and dehydrated at the ambient situation.

2.2.3. Synthesis of Reinforced Jute Fabric. The reinforcement of the jute material entails the remedy of the material with respective chemical substances to be able to shape the hydrophobic assets of the jute material due to the fact that, in nature, the jute material is hydrophilic which is not appropriate for antenna substrate. In this process, the prehandled jute material is immersed in clean MCP $\left(\mathrm{c}_{4} \mathrm{~h}_{6}\right)$ which is turned into dissolved inside the tub containing respective electricity of hydrochloric acid answer. The dry jute material pattern turned into located inside the answer at $12^{\circ} \mathrm{C}$ and allowed for two hours to exhaust the MCP and dopant answer. Then it turned into reacted with carminic acid of $17-24 \%$ for cochineal death on jute material. The handled jute material is then pressed and dried in an ambient situation to be able to be covered with sodium alginate $\left(\mathrm{NaC}_{6} \mathrm{H}_{7} \mathrm{O}_{6}\right)$. The cochineal is used with arranged Sternorrhyncha, which produces the herbal dye carmine. The bugs are discovered at the pads of prickly pear cacti, gathered via way of means of blow-drying them off the plants, and dehydrated. From the insect, carminic acid was developed using deters predation via way of means of different bugs. Carminic acid, commonly $17-24 \%$ of dried bugs' weight, may be extracted from the frame and eggs and then blended with aluminium or calcium salts to make carmine dye, additionally called cochineal.

\subsection{Design Methodology}

2.3.1. UWB Antenna-FR4 Substrate. In Figure 3(a), the first step of the UWB antenna has a conducting patch of width $W p=20 \mathrm{~mm}$ and length $L p=16 \mathrm{~mm}$ and the feed line has a width of $F w=3 \mathrm{~mm}$ and feed length $F l=18.7 \mathrm{~mm}$. Figure $3(\mathrm{~b})$ shows the next step; the conducting patch is included with the one quasistep of width $W 1=1.6 \mathrm{~mm}$ and length $L 1=3.2 \mathrm{~mm}$ along with the feed. Then Figure 3(c) shows the next step; the conducting patch is included with the second quasistep followed with the first one having the width $W 2=3.6 \mathrm{~mm}$ and length $L 2=2.4 \mathrm{~mm}$ along with the feed. In the next step in Figure 3(d), the conducting patch is included with the third quasistep of width $W 3=6 \mathrm{~mm}$ and length $L 3=1.2 \mathrm{~mm}$, thus reducing the feed length to $F l=11.9 \mathrm{~mm}$.

\subsubsection{UWB Antenna-Jute (Raw and Reinforced). The UWB} antenna with the reinforced jute substrate is handcrafted with the conducting copper tape of thickness of $T=70$ microns. Since the dielectric constant of the substrate is not known, the simulation testing is not possible so that the testing results are made to compare with the other commercial substrate having similar structures and similar dimensions (see Figure 4). The geometrical parameters of the jute fibres FR4 UWB and reinforced jute UWB antenna structure are tabulated in Table 1.

\section{Results and Discussion}

This chapter deals with the results of the individual antenna. It includes a return loss graph that shows $-10 \mathrm{~dB}$ bandwidth, Smith chart from where the impedance matching, gain and directivity graph, and maximum power radiated from an antenna can be found, and circular and linear polarization of individual antenna and antenna parameter that shows 


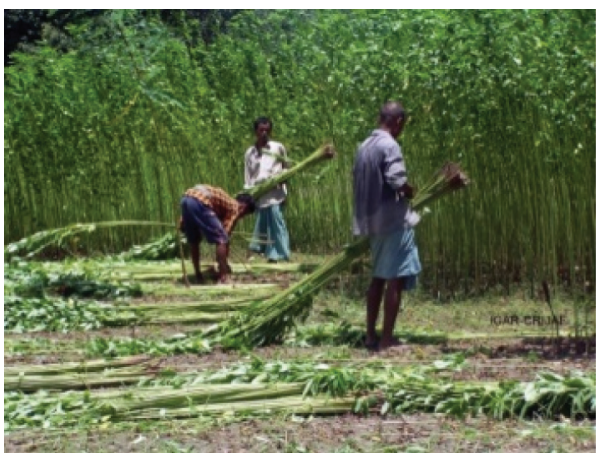

(a)

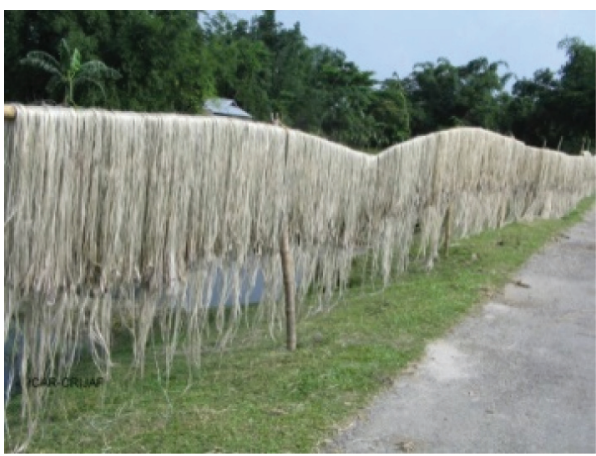

(c)

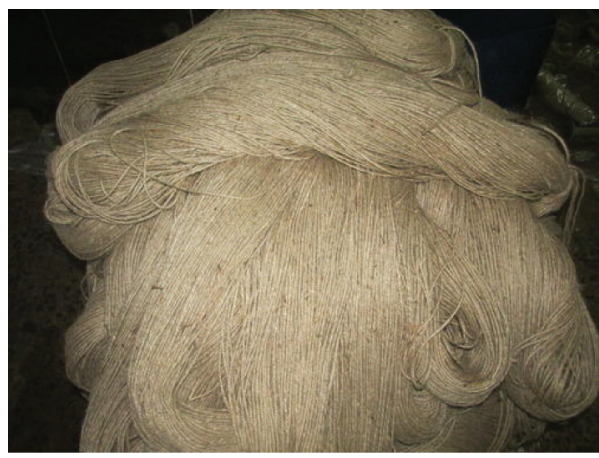

(e)

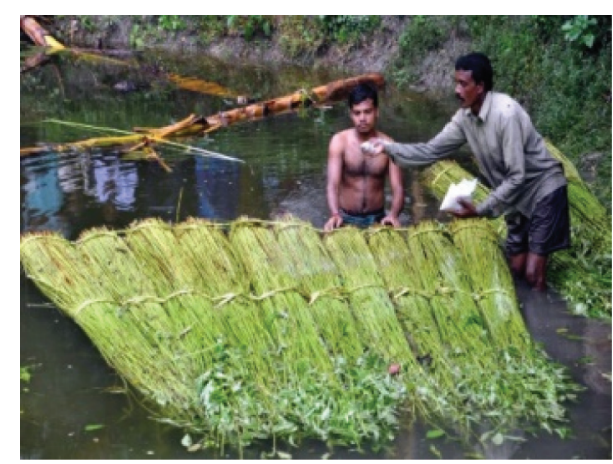

(b)

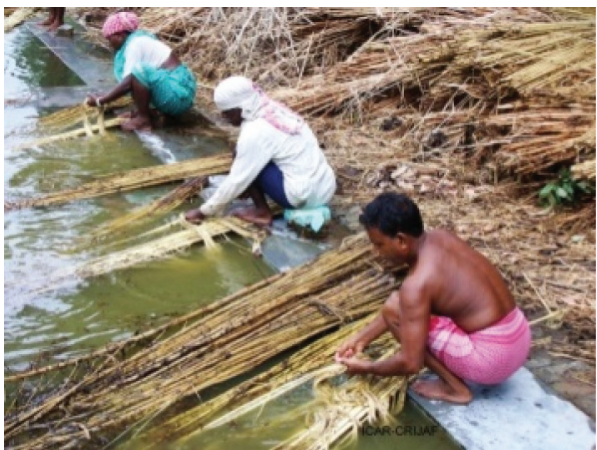

(d)

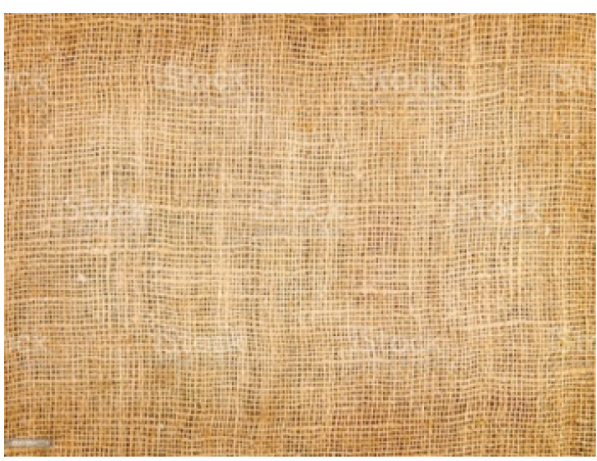

(f)

Figure 1: Process of jute fibres to jute fabric. (a) Bundle stalk. (b) Retting. (c) Sundry. (d) Strapping and washing. (e) Jute yarn. (f) Jute sack.

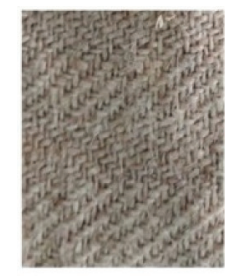

Non-ionic detergent treated Jute fabric
Treatment with 1-Methylcyclopropene on Jute fabric at $\sim 12^{\circ} \mathrm{C}$

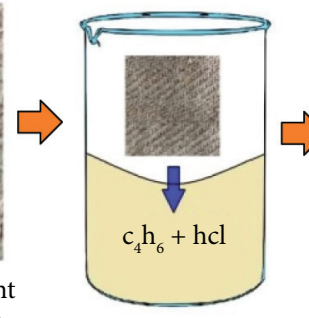

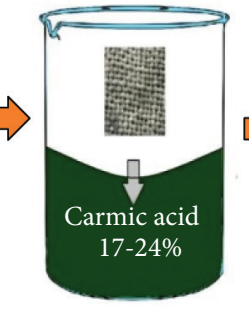

Cochineal dyed on Jute fabric

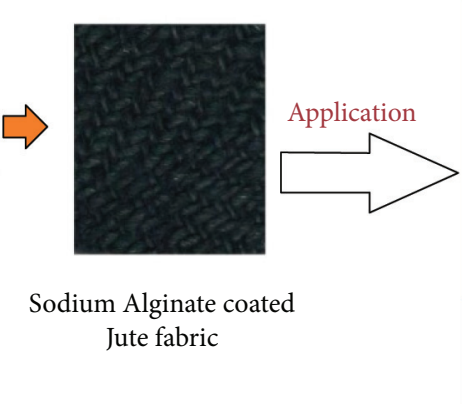

FIgURE 2: Sodium alginate-coated jute synthesis. 


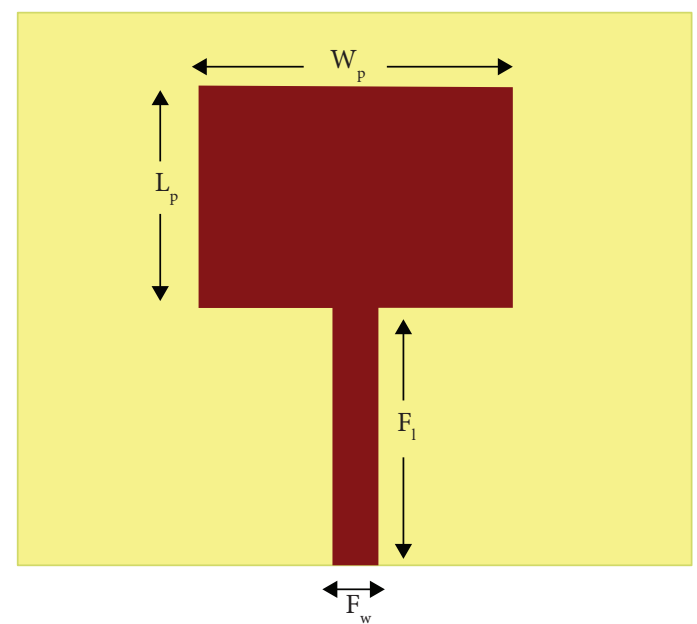

(a)

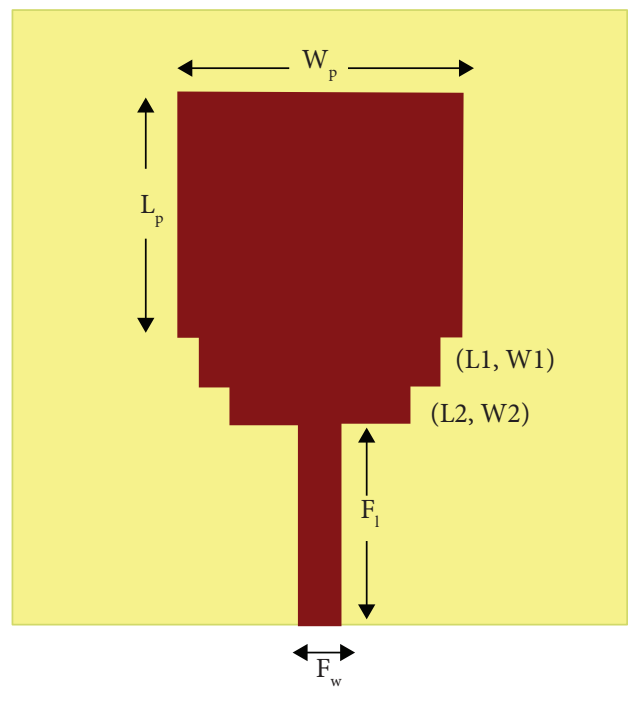

(c)

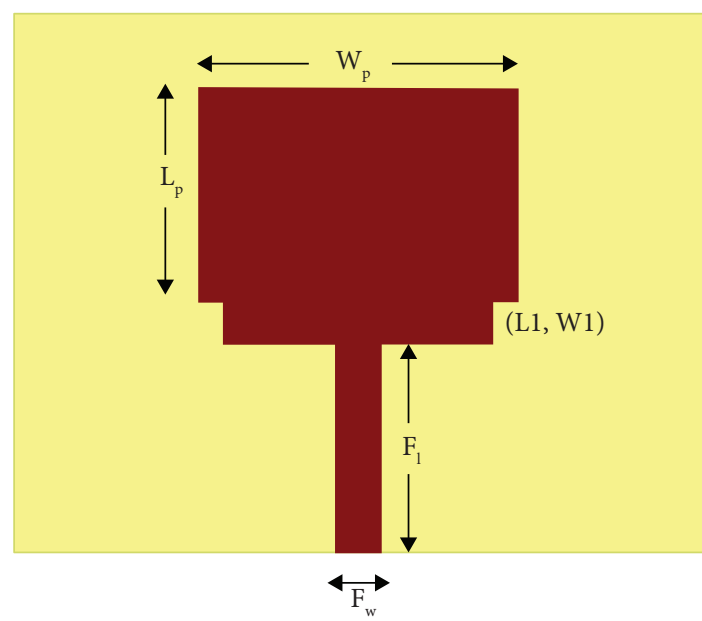

(b)

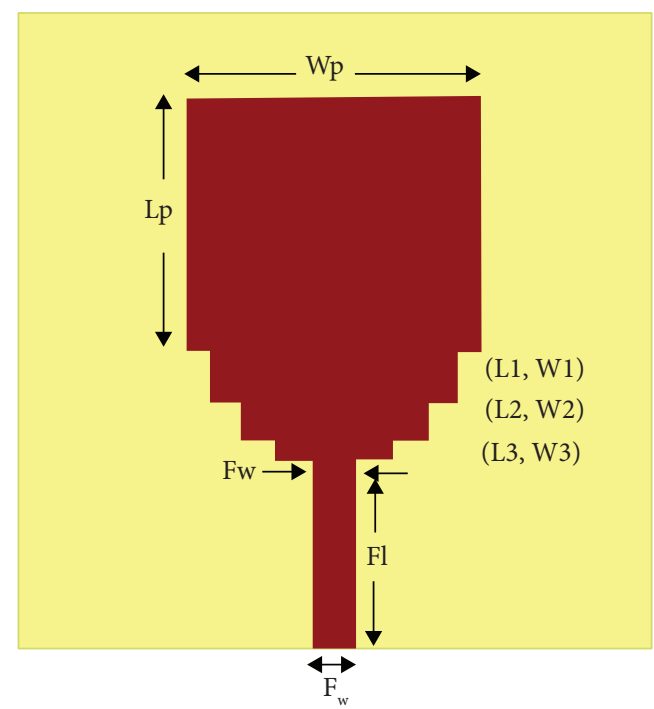

(d)

FIGURE 3: UWB antenna with the FR4 substrate. (a) UWB antenna with no step patch. (b) UWB antenna with one-step patch. (c) UWB antenna with two-step patch. (d) UWB antenna with three-step patch.

obtained gain and directivity; finally, the comparison table gives the result of the existing and proposed method.

Figure 5 shows the parameter study by altering the conducting patch structure by including the quasisteps. No step patch structure gives poor return loss. When one quasistep is included, the return loss is reduced for some frequencies. In addition to the second quasistep, the bandwidth becomes wider than the previous structure. When the three quasisteps were present, the bandwidth along with the return loss was much better improved. It is concluded that the patch with three quasisteps will give satisfactory results so it is selected for further analysis and studies.

Figure 6 shows the parameter study by altering the ground structure. Partial ground structure gives the return loss greater than $-10 \mathrm{~dB}$ at certain frequencies. Feed length ground shows a reduced return loss at several ranges of frequencies when compared to partial ground.
When the ground size is further reduced below the feed length, the wideband having $-10 \mathrm{~dB}$ return loss is attained. When the ground structure is cut at the centre, it shows further improved response with significant return loss and it is concluded that the ground with low ground cut gives ultra-wideband with the coverage of 2.2 GHz-18.65 GHz.

Figure 7 shows the $S_{11}$ graph where $X$-axis frequency is in $\mathrm{GHz}$ and $Y$-axis lies the return loss in $\mathrm{dB}$, and the return was identified for the frequency range obtained from $2.2 \mathrm{GHz}$ to $18.65 \mathrm{GHz}$. The $-10 \mathrm{~dB}$ bandwidth obtained is 16.4395 . The four peaks in this graph represent the rejection of four different frequencies during the transmission. The scattering parameter of the input port is the complex number $S_{11}$ to determine the loss in the UWB antenna. The peak frequency regions are $(4.6-5.4 \mathrm{GHz}),(10.4-11.2),(13.5-14.3)$, and (16.6-17.2), which state that the antenna provides the fractional bandwidth. 


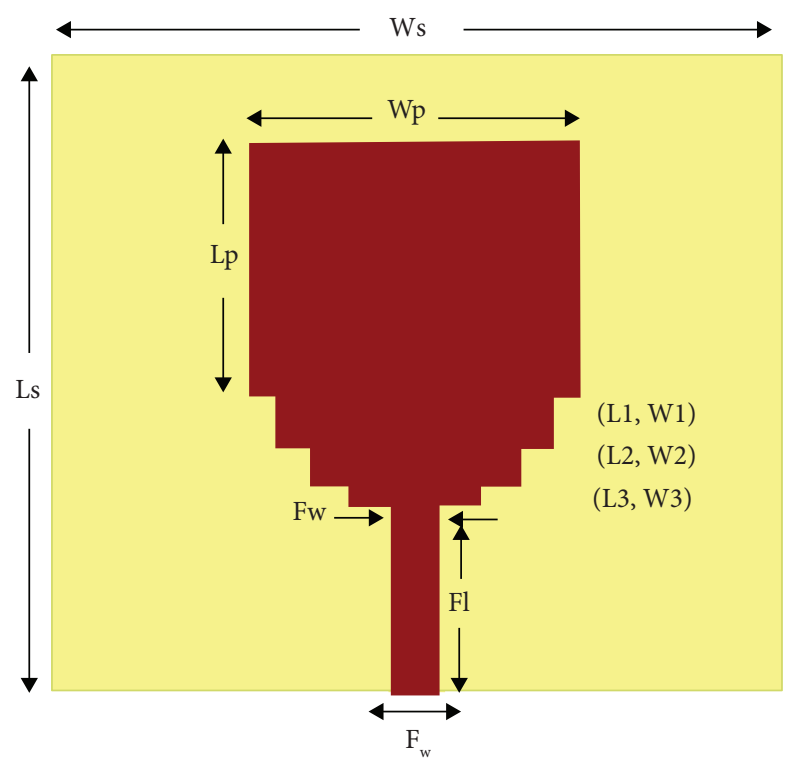

Figure 4: Reinforced jute UWB antenna.

TABLE 1: Geometrical parameters of the FR4 UWB and reinforced jute UWB antenna structure.

\begin{tabular}{|c|c|c|c|}
\hline Parameters & Description & FR4 UWB (mm) & Reinforced jute UWB (mm) \\
\hline$H$ & The thickness of the substrate & 1.6 & 1.25 \\
\hline$W_{s}$ & Width of the substrate & 43 & 1.5 \\
\hline$L_{s}$ & Length of the substrate & 40 & 43 \\
\hline$W_{p}$ & Width of the patch & 20 & 40 \\
\hline$L_{p}{ }^{P}$ & Length of the patch & 16 & 20 \\
\hline$F_{w}$ & Width of the feed & 3 & 16 \\
\hline$F_{1}$ & Length of the feed & 11.9 & 3 \\
\hline$L 1$ & Length of the quasistep 1 & 3.2 & 11.9 \\
\hline$L 2$ & Length of the quasistep 2 & 2.4 & 3.2 \\
\hline$L 3$ & Length of the quasistep 3 & 1.2 & 2.4 \\
\hline$W 1$ & Width of the quasistep 1 & 1.6 & 1.2 \\
\hline$W 2$ & Width of the quasistep 2 & 3.6 & 1.6 \\
\hline$W 3$ & Width of the quasistep 3 & 6 & 3.6 \\
\hline$W_{g}$ & Width of the ground plane & 43 & 6 \\
\hline$W g c$ & Width of the ground plane cut & 3 & 3 \\
\hline $\operatorname{Lgc}$ & Length of the ground plane cut & 8 & 8 \\
\hline Gnd $h$ & Ground plane height & 11 & 11 \\
\hline
\end{tabular}

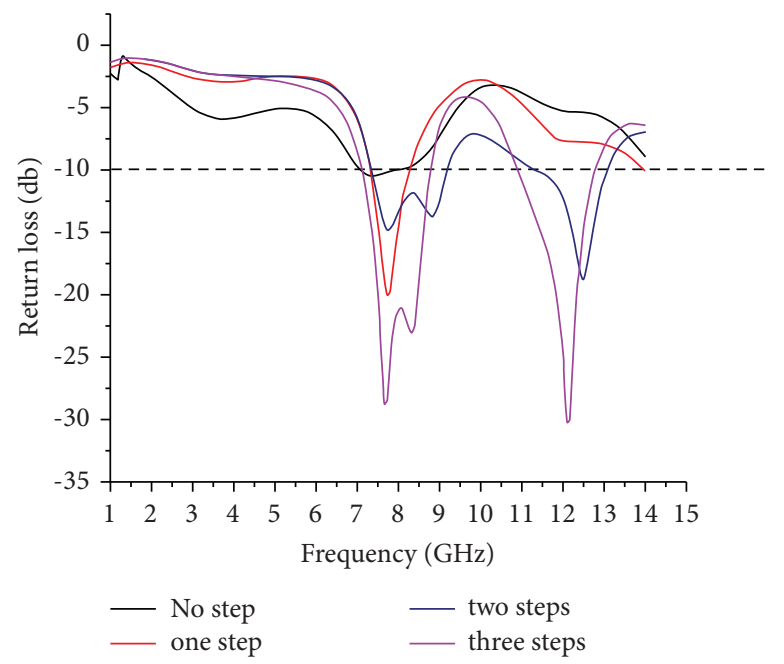

FigURE 5: FR4 substrate parameter study of patch size. 


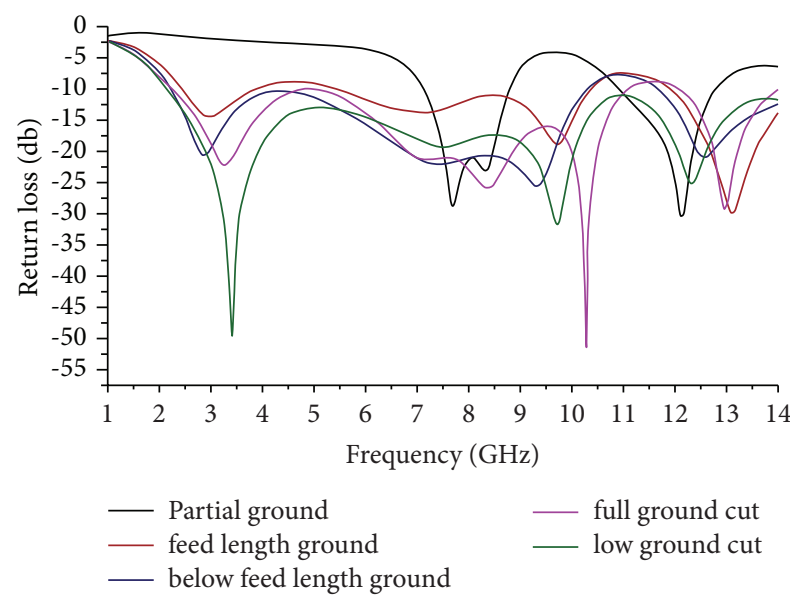

Figure 6: Parameter study of ground size.

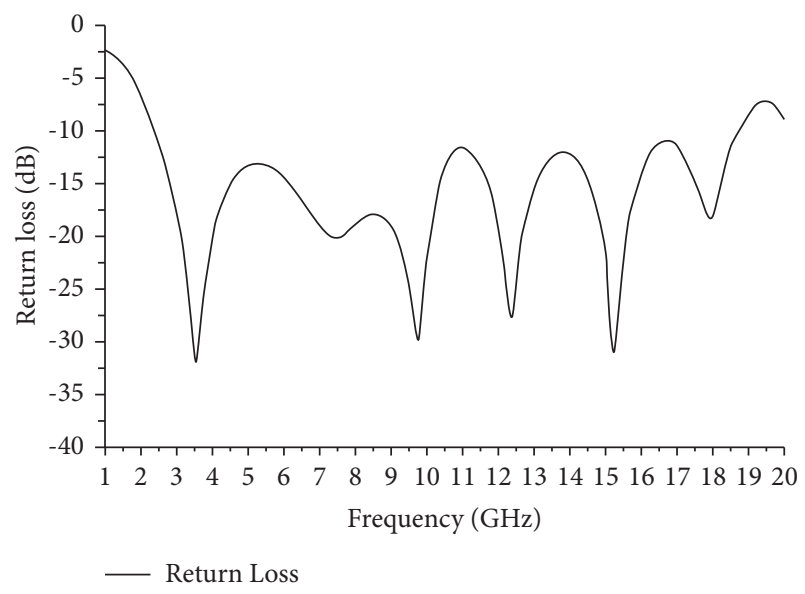

FIgURe 7: The return loss of the FR4 UWB antenna.

A radiation pattern is a measure of its power or radiation distribution around the antenna. Figure 8 shows the radiation/far-field pattern of the designed UWB antenna, and Figure 9 represents a polar plot of the far-field at the central operating frequency. The radiation pattern is also known as a far-field pattern which is used to determine the farthest region away from the antenna irrespective of the distance. The distribution of field and power is independent of distance. It refers to the angular (directional) dependence of the strength of radio waves from the antenna (power radiated from the antenna). It shows that the maximum radiation in red colour is $-10 \mathrm{~dB}$. The value obtained is $5.8718 \mathrm{~dB}$, and the minimum value is indicated in blue colour.

Antenna parameters in Table 2 give the gain, and directivity in $\mathrm{dB}$ power radiated is given in watts. The gain obtained is $5.818 \mathrm{~dB}$. Directivity obtained is 4.5247 . The radiated power is 0.84739 watts.

According to Table 3, thus by comparing the existing and proposed UWB antennas, the fractional bandwidth (FBW) is increased to $157.7 \%$ with the gain of $5.9 \mathrm{~dB}$. The proposed antenna also has a decreased antenna size. As shown in the table, the bandwidth, gain, directivity, and efficiency are increased when compared to the existing antennas.

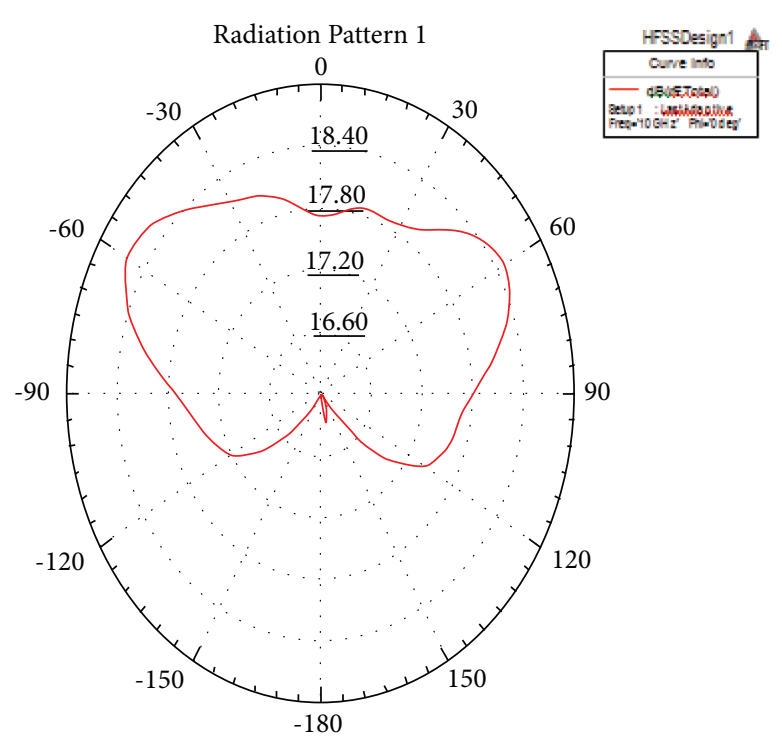

FIGURE 8: The radiation pattern of the FR4 UWB antenna.
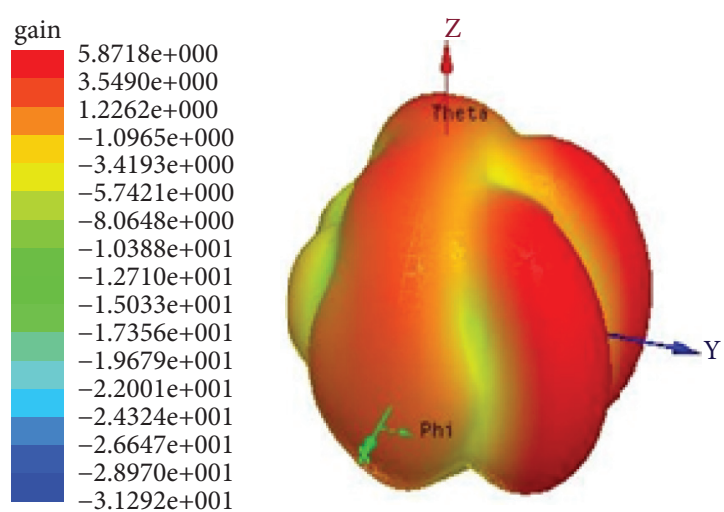

FIgURE 9: The gain pattern of the FR4 UWB antenna.

TABLE 2: Antenna parameters of the FR4 UWB antenna.

\begin{tabular}{lcc}
\hline Quantity & Value & Units \\
\hline Max U & 0.30511 & $\mathrm{~W} / \mathrm{sr}$ \\
Peak directivity & 4.5247 & \\
Peak gain & 3.8652 & \\
Peak realized gain & 3.8342 & \\
Radiated power & 0.84739 & $\mathrm{~W}$ \\
Accepted power & 0.99197 & $\mathrm{~W}$ \\
Incident power & 1 & $\mathrm{~W}$ \\
Radiation efficiency & 0.85425 & \\
Front to back ratio & 10.023 & \\
\hline
\end{tabular}

3.1. Fabricated Results. For the UWB antenna with the substrate of jute Rawand, jute reinforced can only be analyzed and studied with the testing results since the parameters required for the simulation are not present. The substrate material is connected to the testing equipment for the analysis of its parameters. Figure 10 represents the testing carried out in the laboratory for USB antenna analysis and testing. Figure 11 shows the $S_{11}$ graph where 
TABLE 3: Comparison of different antenna configurations.

\begin{tabular}{|c|c|c|c|c|c|c|}
\hline Ref. no. & Antenna type & Freq. (GHz) & ABW $(\mathrm{GHz})$ & FBW (\%) & Material & Area $(\mathrm{LxW})$ \\
\hline $\begin{array}{l}13] \\
\end{array}$ & Patch antenna & $2.33-12.4$ & 10.064 & 136.50 & FR4 $\varepsilon_{r}=4.4$ & $1720 \mathrm{~m}^{2}$ \\
\hline$[14]$ & Planar antenna & $2.5-12$ & 9.5 & 131.10 & RO3003h $\varepsilon_{r}=3$ & $2500 \mathrm{~m}^{2}$ \\
\hline$[15]$ & SRR-loaded UWB antenna & $2.37-10.93$ & 8.56 & 128.70 & Taconic $\varepsilon_{r}=2.33$ & $2500 \mathrm{~m}^{2}$ \\
\hline \multirow[t]{2}{*}[16]{} & Ring slot antenna & $2.5-11.6$ & 8 & 114.20 & $\mathrm{RO} 4003 \mathrm{~B} \varepsilon_{r}=3.4$ & $12000 \mathrm{~m}^{2}$ \\
\hline & Proposed antenna & $2.2-18.65$ & 18.65 & 157.70 & $\mathrm{FR} 4 \varepsilon_{r}=4.4$ & $1720 \mathrm{~m}^{2}$ \\
\hline
\end{tabular}

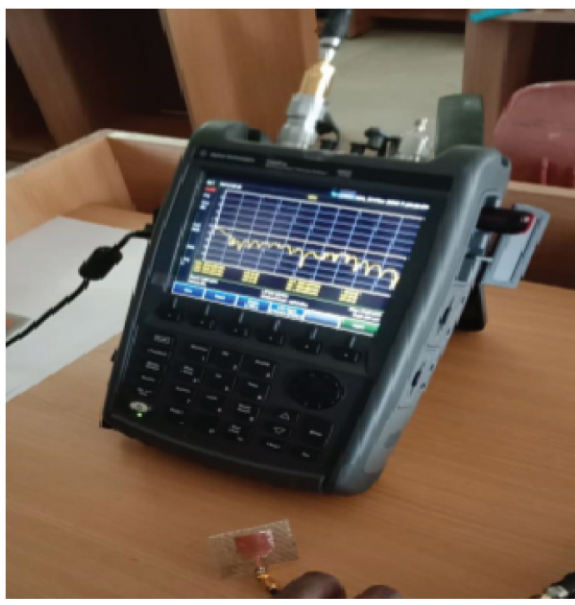

(a)

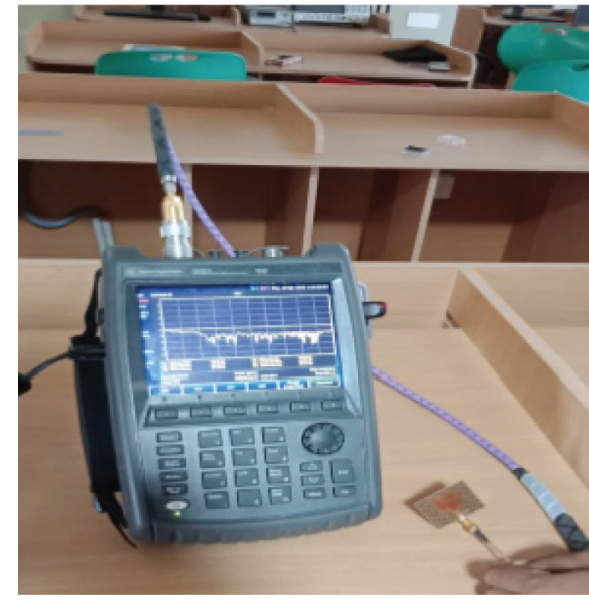

(b)

FIGURE 10: Fabricated antenna testing. (a) Jute raw testing. (b) Jute reinforced testing.

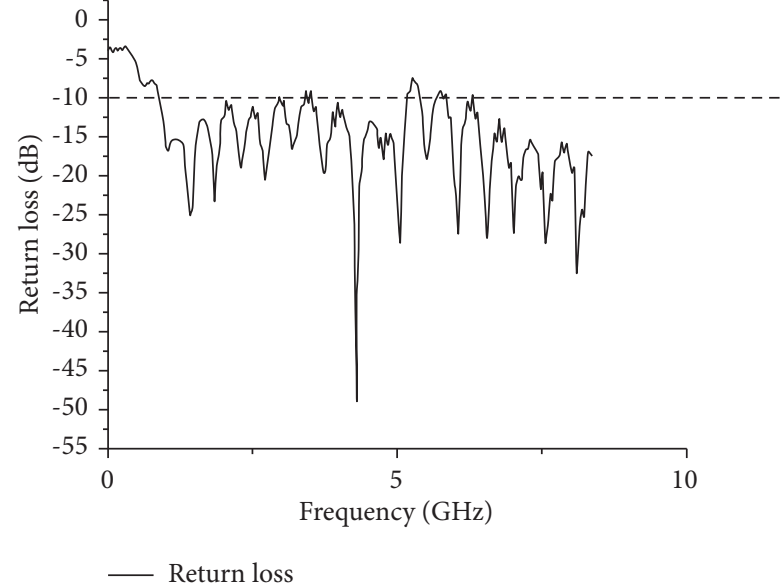

(a)

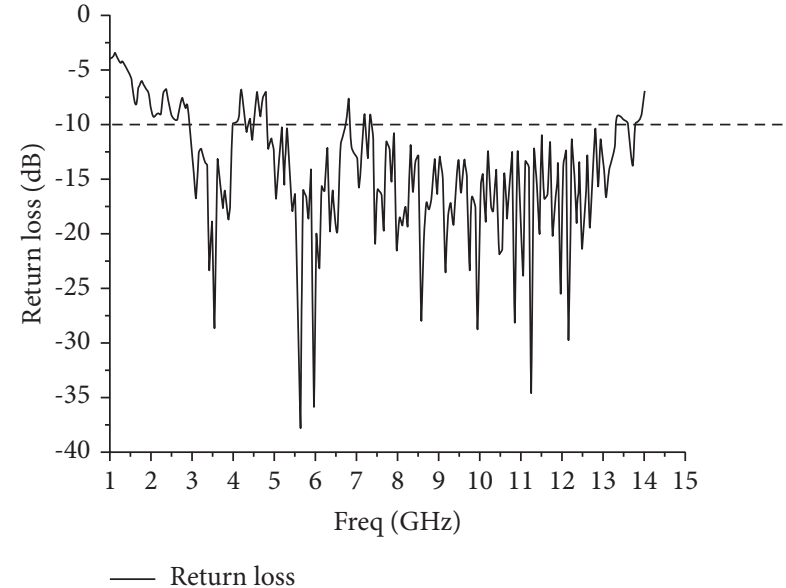

(b)

FIgURE 11: Return loss graph. (a) Antenna return loss in jute raw. (b) Return loss of the jute reinforced antenna.

frequency in $\mathrm{GHz}$ was taken in the $X$-axis and $Y$-axis lies the return loss in $\mathrm{dB}$, the frequency range is not an ultrawideband but it shows multiple bandwidths with multiple frequencies when compared to FR4 substrate. The return losses for jute raw (Figure 11(a)) and jute reinforced antenna (Figure 11(b)) were shown. The return loss in Figure 11 shows that more amount of power is present in the antenna and the loss percentage is less. It was identified that the jute material tries to retain its high power transmission to avoid losses. In Figure 11(b), the frequency range obtained is not ultra-wide, and some of the frequency is not in $-10 \mathrm{~dB}$ so the coverage is not wider but the return loss of particular frequencies goes below $-35 \mathrm{~dB}$. The simulation results using the VSWR technique at the specific operating frequency are shown in Figure 12. VSWR (Voltage Standing Wave Ratio) is the reflection coefficient, which describes the power reflected from the antenna. The VSWR is always real and positive. The antenna is well matched to the transmission line and the power delivered is high for smaller values of VSWR. Figure 12(a) shows the VSWR of jute raw antenna 


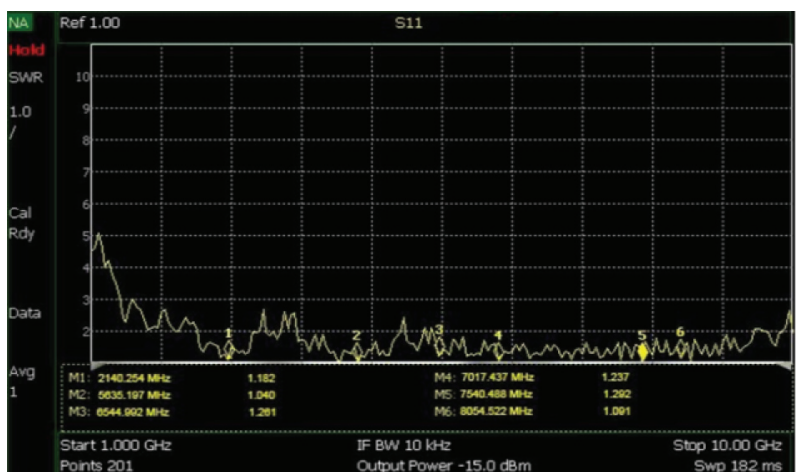

(a)

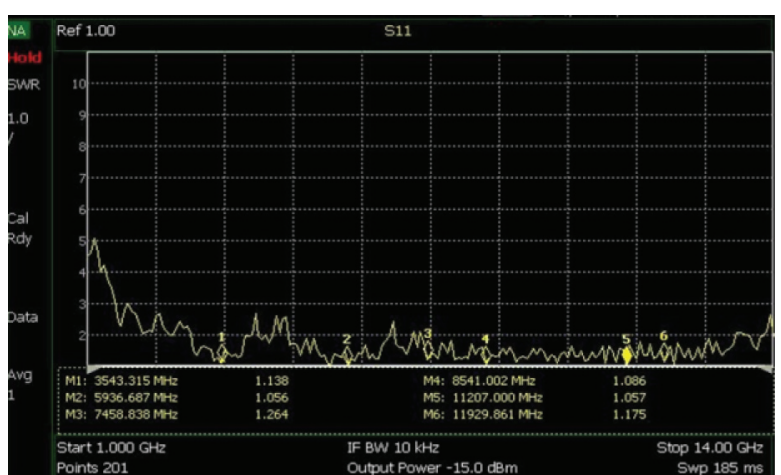

(b)

FIGURE 12: (a) VSWR of the jute raw antenna. (b) VSWR of the jute reinforced antenna.

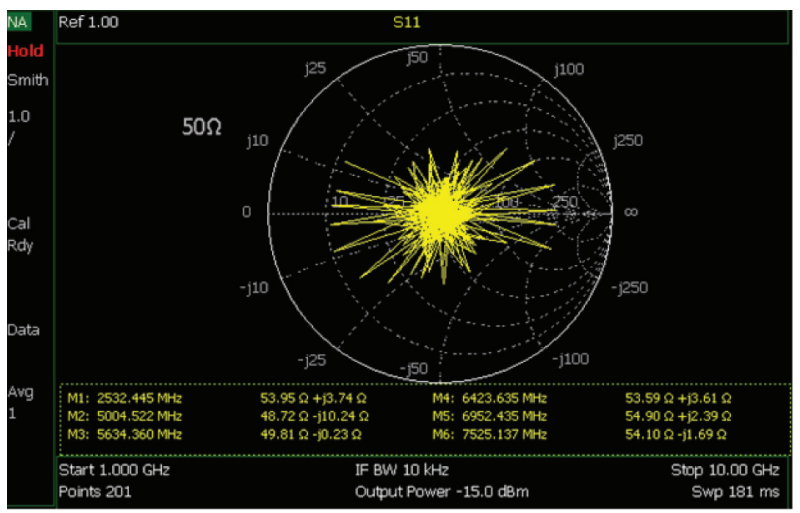

(a)

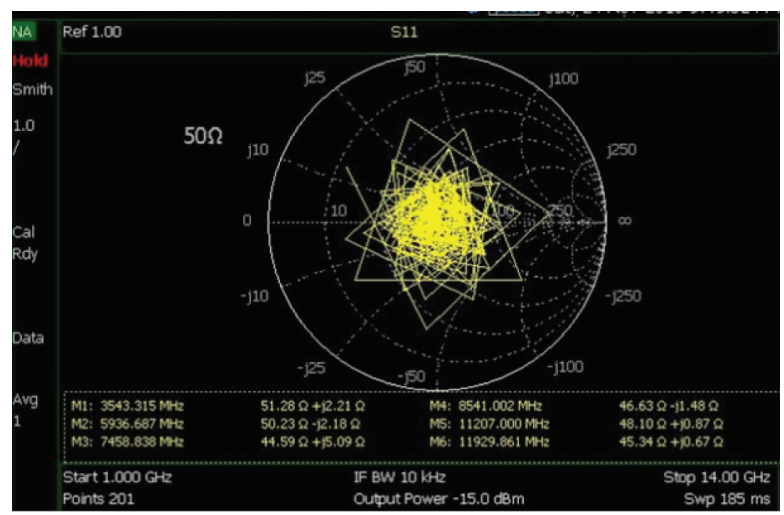

(b)

Figure 13: (a) Smith chart of the jute raw antenna. (b) Smith chart of the jute reinforced antenna.

for the frequency range of $1 \mathrm{GHz}$ to $10 \mathrm{GHz}$. Figure 12 (b) shows the VSWR of jute reinforced antenna for the frequency range of $1 \mathrm{GHz}$ to $14 \mathrm{GHz}$. It was identified that jute reinforced antenna provides a better transmission.

Figures 13(a) and 13(b) show the Smith chart result for jute raw and jute reinforced antenna. The Smith diagram attributes the microwave parts of the jute materials. The input impedance from Figure 13 provides the results within a frequency range where the scattering of transmission was avoided. The results were predicted for jute materials that can be able cover the wide bandwidth ranges. The fractional bandwidth of $157.70 \%$ was achieved with high efficiency.

\section{Conclusion}

A UWB Microstrip patch antenna using a different jute substrate has been designed. The jute substrate with various concentrations of chemicals of reinforced antennas gave different numerical results like gain and frequency; return loss provides satisfactory results for analysis. It is concluded that the jute can act as a substrate for an antenna and it can be a replacement for other commercial high-cost substrates. In this work, the antenna is designed with high fractional bandwidth of up to $18.65 \mathrm{GHz}$ for energy harvesting applications. But for the jute substrate, the results were not ultra-wideband due to the nonlinear structure of the jute substrate where an antenna must have a nonairgap structure. Because of this, the results may slightly degrade in some frequencies. If the antenna is designed with the proper procedure and its physical structure is taken care of, the jute antenna will work better with our expectations. The jute can provide a frequency range of 2.2 to $18.65 \mathrm{GHz}$ with FBW of $157.70 \%$ and the area required about $1720 \mathrm{~m}^{2}$ for jute Microstrip.

\section{Data Availability}

The data used to support the findings of this study are included in the article. Should further data or information be required, these are available from the corresponding author upon request.

\section{Disclosure}

This study was performed as part of the Employment Hawassa University, Hawassa, Ethiopia.

\section{Conflicts of Interest}

The authors declare that there are no conflicts of interest regarding the publication of this paper. 


\section{Acknowledgments}

The authors thank the Management of Saveetha School of Engineering, SIMATIC, Saveetha University, and Sathyabama Institute of Science and Technology for their appreciation and encouragement to complete this research work with in-house research facilities.

\section{References}

[1] A. Geß, M. Lorenz, A. Tolsdorf, and S. Albrecht, "Environmental impacts of renewable insulation materials," Sustainability, vol. 13, p. 8505, 2021.

[2] Z. Ullah and Z. Ul Abedin, "Design of a microstrip patch antenna with high bandwidth and high gain for UWB and different wireless," Applications" International Journal of Advanced Computer Science and Applications (IJACSA), vol. 8, no. 10, 2017.

[3] D. Kim, "Performance of UWB wireless telecommunication positioning for disaster relief communication environment securing," Sustainability, vol. 10, p. 3857, 2018.

[4] J. Liu, H. Peng, C. Wang, and L. Zhao, "Novel SRR-loaded CPW-fed UWB antenna with wide band-notched characteristics," International Journal of Microwave and Wireless Technologies, vol. 9, no. 4, pp. 875-880, 2017.

[5] A. Folino, A. Karageorgiou, P. S. Calabrò, and D. Komilis, "Biodegradation of wasted bioplastics in natural and industrial environments: a review," Sustainability, vol. 12, p. 6030 , 2020.

[6] D. Filonov, J. Hong, K. Kanjanasit, A. Rusakov, and I. Vendik, "Ultrawideband (UWB) planar antenna with single-, dual-, and triple-band notched characteristic based on electric ring resonator," IEEE Antennas and Wireless Propagation Letters, vol. 16, 2017.

[7] I. Sfar and L. Osman, "Development of dual-band wearable textile antenna for WLAN applications," in Proceedings of the 2015 IEEE 15th Mediterranean Microwave Symposium (MMS), December 2015.

[8] G. Dadashzadeh, M. Fardis, F. Geran, N. Hojjat, M. Roshandel, and S. Sadat, "A compact microstrip squarering slot antenna for uwb applications," in Proceedings of the 2006 IEEE Antennas and Propagation Society International Symposium, pp. 4629-4632, Albuquerque, New Mexico, July 2006.

[9] S. Das, "Study of jute composite and its applications," in Proceedings of the International workshop IJSG, Dhaka, Bangladesh, February 2009.

[10] M. Jawaid, Y. A. Othman, M. T. Paridah, and N. Saba, "A review on dynamic mechanical properties of natural fibre reinforced polymer composites," Construction and Building Materials, vol. 106, 2015.

[11] A. Razaq, A. A. Khan, M. H. Asif, S. Iqbal, J. Ali, and F. Manzoor, "Dielectric studies of Environmentally friendly and flexible lignocelluloses fibrils for miniaturization of patch antenna," Modern Physics Letters B, vol. 29, Article ID 1550187, 2015.

[12] L. A. Dong, A. C. Paulo, Q. Wang, X. Fan, and Y. Yu, "Hydrophobic surface functionalization of lignocellulosic jute fabrics by enzymatic grafting of octadecylamine," International Journals of biological macromolecules, vol. 79, 2015.

[13] Q. Ain and N. Chattoraj, "A compact novel tapered U slot ultra wideband antenna," International Journal of Applied Science and Engineering, vol. 11, no. 3, pp. 301-315, 2013.
[14] D. H. Leeand and D. H. Kim, "Effectofirradiation on the surface morphology of nanostructured superhetrophobic surfaces fabricated by ion beam irradiation," Applied Surface Science, vol. 477, 2017.

[15] S. Badhulika, S. Kanaparthi, and V. Raja Sekhar, "Flexible,ecofriendly and highly sensitive paper antenna based electromechanical sensor for wireless human motion detection and structural health monitoring," Extreme Mechanic Letters, vol. 9, 2016.

[16] B. K. AtifShamim, M. F. Farooqui, M. Vaseem, and R. Muhammad Bilal, "A Wearable Tracking Device InkjetPrinted on Textile," Microelectronics Journal, vol. 65, 2017. 